\title{
COSMOPOLITISMO, EXCENTRICIDAD Y MEZCLA EN LOS ENSAYOS DE VICTORIA OCAMPO
}

\author{
María Celia Vázquez \\ (Universidad Nacional de Sur, Bahía Blanca)
}

En 1969, ante el inminente alunizaje de la Apolo XI, Victoria Ocampo escribió un alegato a favor de los derechos del hombre entre los cuales incluye que la humanidad pueda sentirse ciudadana del mundo. A propósito, no duda en confesar el optimismo que le provoca la caminata lunar. ¿En qué sentido este acontecimiento, que sin dudas se destacó entre los principales del siglo XX, le permite vislumbrar un futuro más promisorio a esta confesa cosmopolita que dedicó su vida a forjar una modernidad cultural en Latinoamérica promoviendo redes transculturales mediante viajes, traducciones e infinitos gestos de hospitalidad a artistas, escritores, músicos y cineastas extranjeros (preferentemente europeos)? Sin duda, en la profesada esperanza se traduce la efusión universalista: «obligatoriamente, Ilegará el día en que cualquier hombre hablará como Sócrates. Cuando le preguntaron al griego de dónde era, no dijo: "De Atenas". Dijo: "Del Mundo"» [Ocampo 1971:195]. No es que la ensayista sueñe con una ciudadanía a escala interplanetaria, más bien confía en que, a partir de la concreta expansión del hombre en el universo, las fronteras geopolíticas, así como también las restricciones impuestas en nombre de la nacionalidad o de la extranjería, no pueden sino encontrar su carta de defunción.

¿Qué ideas de mundo convoca Victoria Ocampo al remontarse a los orígenes clásicos de la tradición occidental; cuáles son esos deseos que la llevan a aspirar a la universalidad? Precisamente, Mariano Siskind define como «deseos de mundo» la estructura epistemológica y las pulsiones libidinales conforme a las cuales se configuran las subjetividades cosmopolitas en el caso de los escritores, artistas y críticos latinoamericanos. En primer lugar, para Ocampo el mundo no se corresponde con el globo terráqueo sino más bien con aquellos espacios que habita sobre todo 
«con el pensamiento, la imaginación y el deseo» [1946:202]. Desde esta perspectiva, la pasión del universo (como le gusta decir a la ensayista citando a Paul Claudel) ${ }^{1}$ remite menos a un universalismo abstracto que a otro particular acotado a Europa, o más precisamente a Francia e Inglaterra, cuyas culturas aprendió a amar desde muy pequeña a través de sus lenguas y de su literatura:

El mundo creado por nuestras lecturas era un mundo francés e inglés, puramente, en aquellos primeros años, y tan decisivos que guardo su impronta. Canciones, oraciones, nurseryrhymes, fábulas, cuentos de hadas eran siempre en esos idiomas... [1963:142].

Si, por un lado, la fruición por los libros ingleses y franceses se proyecta en la atracción que siente por esos lugares a los que las lecturas infantiles la transportaban --«Por eso Europa nos atrae irresistiblemente. Su atractivo no es el de lo desconocido sino el de lo ya visto en sueños» [1946:203]-; por otro, aquellos deseos de mundo que le despertó la lectura le permitieron inventar líneas de fuga y resistencias en el contexto de las disputas que, desde los años treinta hasta los setenta, protagonizó con las formaciones culturales nacionalistas de la Argentina del siglo pasado. A propósito, se podría decir sin exagerar que a lo largo de la vida Ocampo tuvo que lidiar con nacionalismos de diverso cuño (católico, restaurador, populista). En la medida en que es en este horizonte de tensiones culturales donde ella se autofigura en tanto intelectual, el agenciamiento cosmopolita debe pensarse no sólo en relación con aquellas pulsiones libidinales sino también como parte de su reacción en contra del carácter opresivo de los particularismos locales, tal como advierte Siskind a propósito de Jorge Luis Borges. Por otra parte, frente a las reiteradas acusaciones de europeísta o extranjerizante de las que fue objeto, la directora de Sur reivindica a los escritores en su condición de «grandes constructores de puentes, de ferrocarriles y de transatlánticos» [1946: 203]. En definitiva, los aprecia en tanto constructores de esas redes que traman cartografías cosmopolitas a partir de «itinerarios globales trazados por desplazamientos y dislocaciones de libros, escritores e ideas» [Siskind 2016: 15].También Borges expresa afinidad selectiva con estas ideas al advertir cuánto se anudan cosmopolitismo y hospitalidad en el caso de Ocampo. Ante la muerte de la escritora, evoca la avidez que sentía aquella para quien el mundo era una fiesta que «le ofrecía muchos sabores»; el «querer gustarlos a todos y que los otros gustaran de ellos» [Borges 1999:329] es lo que la llevó a la asimilación y al consumo de las diversas culturas, preferentemente de la europea, y a la hospitalidad, que tal como la ejerció

\footnotetext{
${ }^{1}$ Mediante la expresión de Paul Claudel Ocampo sintetiza «la apertura al mundo de las ideas, de las letras, de las artes» que singulariza el cosmopolitismo de los más «ilustres argentinos»", como son los escritores Jorge Luis Borges y Ricardo Güiraldes.
} 
Ocampo, según entiende Borges, consiste más en esto de «recibir tantas ulturas, tantos países a través de su memoria llena de versos en diversos idiomas» [1999:329], que en la profesada generosidad de ofrecer su casa a tantos ilustres invitados.

Más allá de los deseos de mundo, la avidez que siente por la tradición europea, en buena medida, también depende de la carencia que padece por ser sudamericana/argentina, según ella misma lo expresa a través de la metáfora del hambre en la «Carta a Virginia Woolf», esa suerte de prólogo que coincide con el inicio exacto de los Testimonios: «Todos los artículos reunidos en este volumen (al igual que los de él excluidos) escalonados a lo largo de varios años tienen en común entre sí que fueron escritos bajo ese signo. Son una serie de testimonios de mi hambre. ¡De mi hambre tan auténticamente americana!» [1935:11]. Al autorrepresentarse tratando de engullir los frutos de la civilización europea para saciar «el hambre» voraz que le produce venir de un continente como el sudamericano, que, a su juicio, todavía es, a pesar del proceso de modernización en curso, un «desierto de expresión», como lo demuestra incluso su mejor literatura, condenada, a causa de la «supremacía del alma y de la sangre», a cierta incompetencia comunicativa.

El deseo de asimilar, engullir, devorar lo que no se tiene indica la posición periférica al mismo tiempo que revela hasta qué punto las experiencias de desposesión son inherentes al proceso de subjetivación cosmopolita. Como advierte Lacan «el deseo es una relación de ser a falta. Esta falta es, hablando con propiedad, la falta de ser» [cit. por Siskind 2016:23]. Debido a esa falta de ser a la que alude Lacan, la identidad marginal se piensa en términos relacionales, de partición e intercambio entre Europa y América del Sur. Por consiguiente, Victoria Ocampo se construye como sudamericana basándose en imágenes de desposesión, ausencia e incertidumbre; en sentido inverso asocia la identidad europea con propiedad, posesión, pertenencia, todas ideas sugerentes de un «sentimiento de plenitud». Este sentimiento se corresponde con el estado de sujeto a quien nada le falta, como si la condición europea remitiese a una identidad «saciada (...) que no puede conducir más que a representaciones claras y definitivas» [Laplantine y Nouss 2007:24]. En estos términos evoca a Virginia Woolf en ocasión de narrar cuando se conocieron; específicamente la asimetría entre las dos mujeres se traduce en las distintas miradas, que a su vez traducen las actitudes que cada una adopta ante la otra, según la versión de la escritora sudamericana: «Yo la miré con admiración. Ella me miró con curiosidad. Tanta curiosidad por una parte y, admiración por otra, que en seguida me invitó a su casa» [1979: 41]. 
'Admiración' y 'curiosidad' son los significantes escogidos por Ocampo para establecer la diferencia que existe entre «esas dos mujeres que son significadas desde oposiciones radicales y jerárquicas» [Salomone 2006]; en la de/gradación axiológica que se juega entre ambas escritoras — «la una adosada a una formidable tradición y la otra al vacío» [Ocampo 1982 [1954]:101102]— se afirma la desigualdad que existe entre dos mundos radicalmente diferentes, tan distantes, tan distintos como Virginia y Victoria. El mismo sentido de desigualdad sugieren las metáforas del cactus y del jardín francés que utiliza en el obituario de Paul Valéry: «Un cactus es, claro está, cosa extraordinaria en el país de los rosales bien podados y de los frutales en espalier» [1946a:119-120]. Conforme a aquella tesis según la cual el continente americano se corresponde con la naturaleza y Europa con la civilización, Ocampo escoge esas imágenes para aludir a sí misma y al escritor, respectivamente. Pero sobre todo lo hace para construirse como un sujeto exotizado a partir de la adopción de la perspectiva de ella que tiene el escritor francés, como si fuese su propia mirada: «¡Pobre planta exótica desamparada! Muestra sin valor de riquezas indemostrables» [1946a:119-120].

El cactus representa la condición elemental de un continente o país que tiene riqueza y belleza, pero invisibles ante los ojos europeos, como lo ilustra la experiencia fallida con Valéry, cuando le muestra una sorprendente fotografía, tomada en Jujuy, de un cactus enorme como un árbol y cubierto de flores, con la esperanza de que el poeta francés admire su belleza, y la respuesta que consigue es: «Debe ser muy feo» [1946a:115]. Por otra parte, al compararse con esta especie botánica para expresar su insignificancia, Ocampo practica una mirada exótica, aunque lo hace invirtiendo el procedimiento que, según Aira, define el exotismo en las Cartas Persas de Montesquieu. Para Aira «los persas son el dispositivo que inventa Montesquieu para generar la mirada» [1993:73-74]. Rica y Usbek pueden ver Europa «como nadie la ha visto antes, como no pueden verla los europeos, que son parte inseparable del fenómeno Europa» [1993:73] debido a su condición de extranjeros. Que esta condición sea lo que les permite «a los persas pasar del ver al mirar» [1993:73] depende menos del hecho de que los protagonistas de la novela se experimenten como extranjeros que de la percepción de los europeos en cuanto extranjeros. Inversamente, Ocampo profesa el exotismo al crear un dispositivo para verse a sí misma a través de los ojos de Woolf y Valéry. En síntesis, se configura como un sujeto exótico porque se percibe desde la distancia imperial que se resume en el imaginario de la esencialidad americana (asociado a la condición primitiva, sin historia, significación 
ni belleza). En conclusión, al contemplarse a sí misma y a su mundo habitual con los ojos que la exotizan, se inventa «como si» fuese una extranjera, «como si» yo fuera Otro.

Si en la perspectiva exótica sólo uno de los términos se define por lo que no es, en el caso de Ocampo, ser americana/argentina es no ser europea. Por lo tanto, al exotizarse, está simultáneamente reconociendo la superioridad europea y asumiendo el carácter minoritario de la cultura americana. Quizás podría pensarse que la escritora se choca con aquello que para Clifford Geertz constituye una dificultad básica de las construcciones identitarias nacionales periféricas, cual es imaginarse a través de términos positivos: «siempre es más fácil definirse como no europeo, o como no británico, que como pakistaní, nigeriano, brasileño, argentino o chileno» [Geertz, cit. por Fernández Bravo 2000:21]. Según el antropólogo, la dificultad aludida proviene de los desajustes y las asimetrías que imponen las temporalidades distintas que cohabitan en una nación.

No obstante la dificultad básica para definirse en términos positivos y los signos de minoridad, en algunas ocasiones Ocampo, a través del recurso de la ironía, se muestra mucho más dueña de sí misma de lo que proclama. Siguiendo las huellas de la ironía, encuentro el relato (no desprovisto de humor) de otra experiencia vivida con Virginia Woolf, que también involucra el exotismo, aunque, en este caso, la escritora argentina se muestra más dispuesta a distanciarse que a adoptar como propia la perspectiva exótica de la inglesa. Por consiguiente, desplaza el foco del relato de la admiración que ella siente por la autora de Orlando a la curiosidad que Woolf siente por ella. En consecuencia, menos que construirse como sudamericana argentina ante la cultura europea, a Ocampo le interesa exponer directamente «la novela exótica» (tomo la clasificación que usa Aira a propósito de la novela de Montesquieu) que compone Woolf y que la tiene como protagonista.

\footnotetext{
Virginia se imaginaba que yo llegaba de una ciudad (Buenos Aires) en que nubes de las más espléndidas mariposas nos persiguen en los jardines, mientras que jóvenes soberbiamente bronceados y de indumentaria tropical toman bebidas frescas bajo quitasoles de vivos colores. Las mariposas pueden haberle venido de Darwin, me decía yo, quien cuenta, en efecto, que el Beagle fue asaltado un día, a 10 millas de la bahía de San Blas, por una verdadera manga de mariposas, a tal punto que los marineros decían que «nevaban mariposas». Pero ¿de dónde le vienen los jóvenes bajo quitasoles? De ninguna parte. De Virginia Woolf, pura y simplemente. [1941:81]
}

En este caso, Ocampo pone el foco en las fabulaciones de Woolf: la inglesa convierte a la escritora, a Buenos Aires, a Sudamérica, en «objetos de curiosidad» en tanto ejemplares de un 
mundo exótico coincidente con la representación claramente ideologizada de las colonias inglesas. Aquí es la perspectiva de la europea la que produce el extrañamiento de la pampa argentina y de la propia Ocampo valiéndose de aquellas «imágenes con que los escritores de la época de la expansión imperialista solían describir esos territorios distantes, misteriosos y violentos» [Salomone, 2006]. Según el ángulo desde el que se mira (el de Woolf o el de Ocampo), el exotismo adquiere diversos significados en el proceso de autofiguración. Cuando es el efecto de la mirada de Woolf y no el resultado del propio artificio, el exotismo deja de ser un síntoma del sufrimiento, la marca de la inferioridad frente a los europeos, para convertirse primero en objeto de risa, luego en oportunidad. A través de esas imágenes que cosecha «la más rica», la escritora argentina no solo percibe que la inglesa la mira como un sujeto exótico ( [I] una parece decir: "He aquí un libro de imágenes exóticas que hojear"», [Ocampo 1935:9]), sino que además reconoce la ignorancia, la incapacidad de Woolf para percibir a esa otra a la que había exotizado y a quien, por ende, no podía considerar en un plano de igualdad consigo misma. Todorov subraya la íntima relación que existe entre exotismo y desconocimiento; más precisamente, define el exotismo como el desconocimiento de los otros, la negativa a verlos tal como son:

\footnotetext{
Nadie es intrínsecamente otro; no lo es más que porque no es yo; al decir de él que es otro, en realidad, nada he dicho aún, y lo que es peor, nada sé yo sobre él, ni nada quiero saber, puesto que toda caracterización categórica me impediría mantenerlo dentro de esta rúbrica puramente relativa, la alteridad. [1991:305; las cursivas son mías]
}

A su modo, Ocampo verifica la tesis de Todorov al corroborar que la escritora inglesa no sabe, sin embargo, quién es ni qué quiere una mujer sudamericana. Ante ese descubrimiento, al mismo tiempo que se ríe de sí misma como sujeto subalternizado, también lo hace de quien ocupa la posición dominante $y$, por consiguiente, es responsable del dispositivo a través del cual ella se mira en cuanto personaje exotizado. En consecuencia, la relación de la escritora argentina con la escritora inglesa se revela como mucho más compleja que lo que parece sugerir Ocampo cuando enfatiza la admiración que siente por aquella y se construye a través de la mirada europea. En este caso, además de burlarse de la ignorancia de Woolf, establece cierta paridad entre ambas mientras le sigue el juego. 
El deslizamiento de la experimentación del exotismo como padecimiento al usufructo de sus beneficios introduce una variación significativa en el proceso de autorrepresentación, que se manifiesta a través de un cambio de tono. Cuando el exotismo es la garantía del interés de Woolf, Ocampo introduce un tono gracioso, humorístico, por momentos irónico, que la lleva, si no a olvidarse, por lo menos a desentenderse de su condición de inferioridad. El carácter lúdico que domina la escena en la que la escritora argentina, según el guión inventado por la escritora inglesa, juega a representar un personaje exótico habitante de un país con "ganado salvaje, hierbas verde azulado de la pampa, mariposas revoloteando en el aire» [1979:43] desbarata la solemnidad y pone entre paréntesis la construcción de su minoridad. El énfasis ya no está puesto en señalar la inferioridad sino en procurar un acercamiento a través de la complicidad:

Me hablaba en sus cartas de nuestras inmensas Ilanuras de un verde azulado. ¿Cómo se llaman? -agregaba entre paréntesis. Han de ser impresionantes como el ganado salvaje, decía. Y yo pensaba al leerla: ¡Santo Dios! Con el trabajo que les ha costado a nuestros estancieros criar vacas, toros, caballos, carneros, dignos de figurar junto a los mejores de Inglaterra (de donde muchos provienen). Pero si te divierte imaginar las cosas así, Virginia, no me opongo. [1979:43; las cursivas son mías]

La decisión de concederle diversión a la inglesa también forma parte de un juego, y nos advierte que en el movimiento de sus partidas se desliza una sutil y delicada ironía. Instalada en este escenario lúdico, entre divertida e irónica, se autorrepresenta dispuesta a jugar mofándose de los disparates de Woolf en calidad de cómplice y no de contrincante. Por eso, desde la primera partida opta por ceder sin contradecir la iniciativa a la otra participante, para reírse juntas de la visión pueril de estas fantasías. En este juego de la complicidad, Ocampo apuesta la ficha más fuerte cuando le regala una caja llena

[...] de las más delirantes mariposas: azules, verdes, rojas, amarillas, marrones con preciosas pintas de otros colores, o rayadas como tigres de Bengala y cebras. Todas aquellas alas habían conocido cielos americanos, el de la cuenca del Amazonas, los del Perú y Colombia, los de Venezuela y Bolivia y hasta el de mi San Isidro. [1982: 95]

A través del regalo, Ocampo concretiza la imagen de Sudamérica que a la escritora inglesa le interesa; las mariposas, como símbolo del exotismo americano, connotan la belleza y la exuberancia naturales que hacen de estas tierras remotas, de acuerdo con la imaginación de Woolf, una suerte de Arcadia, a diferencia del otro símbolo, el cactus, que enfatiza el sentido de la desigualdad cuando, 
por su primitivismo, queda enfrentado con el elegante jardín francés. En conclusión, la astucia la lleva a hacer un uso irreverente de la mirada exótica de la inglesa: al distanciarse (por la vía de la burla y del humor) de los prejuicios de la europea, aquella ya no compone el personaje de sudamericana/ argentina como si fuera una extranjera minor, sino que se comporta como una forastera, según la imagen que emplea Martínez Estrada en alusión al modo irreverente en que Montaigne usa la Antigüedad clásica. Mediante la figura del forastero, Martínez Estrada alude a la actitud desprejuiciada y libre que asume el ensayista francés ante la Cultura y la Tradición. Evidentemente, Ocampo no hace el uso clandestino de la tradición euro-imperial que reivindica Estrada a propósito de Montaigne, pero sí desautoriza la perspectiva de Woolf al mostrar su ignorancia y burlarse de ella.

Entre los recursos tendientes a perforar la subalternidad, sin duda, debe sumarse la idea de mezcla, un concepto a través del cual Ocampo sugiere el potencial creativo que posee la condición marginal de los artistas americanos. No obstante reconocer que la modernización cosmopolita excéntrica no está en perfecta sincronía con la «civilización europea», la escritora reivindica aquellas estéticas o estilos derivados de la libertad que otorga la carencia de una tradición consolidada como ejemplo de esa originalidad genuinamente americana. A propósito dice:

\footnotetext{
Dos mujeres de este siglo me han dado la impresión de ser, por instinto, creadoras e inspiradoras de una estética. Estética que dejó su impronta en varias generaciones. Una lo hizo bailando; la otra arreglando su casa. Ya lo dije en 1950. Ambas americanas, una del norte; otra del sur de nuestro continente: la norteamericana era Isadora, la chilena Eugenia Errázuriz. [1971:147]
}

En qué consisten esas estéticas que para Ocampo se revelan como emblemas de lo americano. En el caso del design que creó esa precursora del minimalismo que fue Eugenia de Errázuriz, la chilena que pasó más de la mitad de su vida en Paris, Biarritz y Londres, la originalidad depende menos de las «mescolanzas atrevidas» que del efecto de discontinuidad y discordancia que provoca la reunión del arte cubista de Picasso con el mobiliario Luis XV y las paredes blanqueadas a la cal. De idéntica manera, aquello que distingue a la coreografía de Isadora remite sobre todo a las discordancias temporales, los anacronismos que se ponen en juego a partir de la mezcla de la música de Chopin con los movimientos corporales procedentes de la antigua Hélade. Se podría decir que, según interpreta Ocampo, la cifra de lo genuinamente americano coincide con aquello que Francois Laplantine y Alexis Nous piensan como «devenir mestizo». En primer lugar, las mixturas de Errázuriz 
y Duncan se corresponden antes que con un procedimiento de ensamblaje con un devenir. Si, según Deleuze, el devenir se define como un encuentro o una relación entre dos términos heterogéneos que se desterritorializan, entonces este

nunca es imitar, ni hacer como, ni adaptarse a un modelo, así fuera de justicia o de verdad. No hay un término del que se parta, ni uno al que se llegue o al que se deba llegar. Tampoco dos términos que se intercambian. [Deleuze 1998:32]

Por otra parte, si mestizaje «es lo que nos arranca de la repetición de lo mismo, de la reproducción de lo compacto en un marco delimitado», entonces, no toda reunión por sí misma es mestiza, sino solo aquella que «adquiere un carácter descentrado, desarticulado, discordante y desincronizado» [Laplantine y Nouss 2007:26].

Para terminar, quisiera volver al comienzo, detenerme en esa petición de principios a favor de la universalidad que hace Ocampo a propósito de los viajes interestelares. En rigor, lo que la ensayista reclama es una universalidad mestiza similar a la que sugieren las obras que por estar «más enraizadas en su tierra la mezclan a todas las tierras» [Ocampo 1941: 98]. Tal es el caso de Cumbres Borrascosas, la novela de Emily Brönte cuya lectura la Ileva a reconocer «su propio y enajenable desierto»:

Y quizá nunca haya comprendido yo mejor lo que significaba para mí el grande y áspero viento de las pampas con su carga de teros gritones que al escuchar gemir el de Wuthering Heights. El viento de Wuthering Heights no llega sino a quienes conocen ya una queja semejante: la que sube desde su propia tierra y desde su propio enajenable desierto.[1941: 98]

En la confluencia del áspero viento británico y el que sube desde la pampa no se traduce sino el punto de convergencia entre cosmopolitismo y nacionalidad en torno al cual construye Ocampo la «argentinidad de extranjerizante»"2 con la que se identifica. Si la novela inglesa la lleva a experimentar lo que hay de más singular y de más universal en el paisaje natal, es porque ella se declara inmune a cualquier pretensión esencialista. Por lo mismo, se resiste a las estrecheces propias de una política identitaria ya que, de acuerdo con la teoría del mestizaje, lo identitario implica una fijación. ${ }^{3}$ A la

\footnotetext{
${ }^{2}$ Ocampo utiliza esta suerte de oxímoron para resumir, a propósito de Güiraldes y Borges, la tesis de que la peculiaridad de la literatura argentina depende de la transmutación de la tradición europea «en algo absolutamente nuestro». Por otra parte, el matiz despectivo que aporta 'extranjerizante' revela que la fórmula posee un carácter defensivo ante las críticas de las que ella misma es objeto por parte de los nacionalistas.

${ }^{3}$ Laplantine y Nous distinguen entre identidad e identitario. Mientras que lo identitario se define en torno a las ideas de pertenencia, de estabilidad y de fijeza, la identidad, en cambio, se refiere a un proceso dinámico de construcción de subjetividades inestables. Por otra parte, dicho proceso implica desequilibrios mestizos y desgarramientos.
} 
vez, piensa su lugar en el mundo alejándose tanto del reflujo de lo que excluye o particulariza como de lo que abstrae o generaliza. En definitiva, las cartografías que traza esta cosmopolita son móviles o más precisamente movidas, como se dice de una fotografía fuera de encuadre. El desencuadre, en este caso, tiene que ver con la inestabilidad, o mejor, como prefiere decir Ocampo, con la oscilación entre estar y no estar que la constituye como sujeto:

Estoy en donde no estoy, como decía Gabriela Mistral. En aquellas horas de lectura, no estaba en San Isidro o en la calle Viamonte 482: estaba en Francia, en Inglaterra. Y ahora, cuando estoy en Francia o en Inglaterra de veras, suelo estar acurrucada en un sillón que lleva las fundas del verano sanisidrense, o junto a una ventana por donde pasan las palomas que viven en las cornisas de las Catalinas. [1963:145] 


\section{BIBLIOGRAFÍA}

AIRA, César: «Exotismo», Boletín del Grupo de Estudios de Teoría Literaria, 3, (1993), pp. 73-79.

BORGES, Jorge Luis: «Borges en Sur; 1931-1980». Buenos Aires: Emecé, 1999.

DELEUZE, Gilles: Diálogos con Claire Parnet. Valencia: Pre Textos, 1998.

FERNÁNDEZ BRAVO, Álvaro (comp.): La invención de la nación. Lecturas de la identidad de Herder a Homi Bhabha. Buenos Aires: Manantial, 2000.

GEERTZ, Clifford: El antropólogo como autor. Barcelona: Paidós, 1997 [1988].

LACAN, Jacques: El Seminario de Jacques Lacan, libro 2, ed. de Jacques -Alain Miller. Buenos Aires: Paidós (1988).

LAPLANTINE François, y Alexis NOUS: Mestizajes; De Arcimboldo a zombi. Buenos Aires: Fondo de Cultura Económica, 2007.

MARTÍNEZ ESTRADA, Ezequiel: Heraldos de la verdad. Buenos Aires: Nova, 1957.

OCAMPO, Victoria: «Carta a Virginia Woolf», Testimonios. Madrid: Revista de Occidente, (1935), pp. 9-17.

__ : «Virginia Woolf, Orlando y Cía», Testimonios; Segunda Serie. Buenos Aires: Sur, (1941), pp. 3-87.

— : «Emily Brönte (Terra incognita)», Testimonios; Segunda Serie. Buenos Aires: Sur, (1941), pp. 95-165.

—_: «Nahuel Huapí», Testimonios; Tercera Serie. Buenos Aires: Sudamericana, (1946), pp. 199-210.

: «Paul Valéry:1871-1945», Testimonios; Tercera Serie. Buenos Aires: Sudamericana, (1946), pp. 113-139.

: «De la cartilla al libro», Testimonios; Sexta Serie (1957-1962). Buenos Aires: Sur, (1963), pp. 134-148.

__ : «El derecho de ser hombre», Testimonios; Octava Serie (1968-1970), (1971), pp. 186-195.

—: «La intraducible Isadora (o el genio de las mujeres de América)», Testimonios; Octava Serie (1968-1970), (1971), pp. 143-147.

_ pp. 40-52.

— Virginia Woolf en su Diario. Buenos Aires: Sur,(1982) [1954]. 
SALOMONE, Alicia: «Virginia Woolf en los Testimonios de Victoria Ocampo: tensiones entre feminismo y colonialismo», Revista chilena de literatura, 69 (2006), pp. 69-87, disponible: http://www.scielo.cl/scielo.php?s

SISKIND, Mariano: Deseos cosmopolitas; Modernidad global y literatura mundial en América Latina. Ciudad Autónoma de Buenos Aires: Fondo de Cultura Económica, 2016.

TODOROV, Tzvetan: Nosotros y los otros. Reflexión sobre la diversidad humana. México: Siglo XXI, 1991 [1989]. 